\title{
SOBRE LA POSTMODERNIDAD Y SU EXPRESIÓN PLÁSTICA
}

\author{
POR FERnANDo Martín Martín
}

\begin{abstract}
El presente artículo examina el fenómeno del Postmodemismo, poniendo especial énfasis en su expresión en las Artes Plásticas. Comienza tratando la clave de las ideas teóricas que lo sostienen y definen, reflejando las opiniones de los principales representantes e intentando establecer las relaciones históricas y sociales que pueden ayudar a la comprensión de sus orígenes. Una segunda parte se centra en la explicación de como la condición y sensibilidad postmodemas se reflejan en la producción pictórica, basada en un número de principios comunes. Finalmente es analizada la situación considerando a las generaciones de artistas que representan este movimiento y a los nuevos canales que los ayudan y promueven, tanto desde el punto de vista crítico, como desde el marco de las exposiciones.
\end{abstract}

The present article examines the phenomenon of postmodernism, with particular emphasis on its expression in the plastic arts. It begins by dealing with the key theoretical ideas which sustain and define it, reflecting the opinions of its main representatives and attempting to establish the historical and social relationships which may help in the understanding of its origins. A second part focuses on an explanation of how the postmodem condition and sensibility is reflected in pictorial production based on a number of common principles, and finally the situation in Spain is analysed, both with regard to the generations of artists who represent it and the new channels which aid and promote it, either from critical standpoints or within the framework of exhibitions.

"Hay que ser modernos". Arthur Rimbaud

"La muerte del arte, como la de los dioses, es un problema de teología y de creyentes".

Juan Antonio Ramírez

El presente texto fue elaborado como conferencia con ocasión del curso que bajo el título Jomadas de Arte Contemporáneo se realizó del 4 al 7 de mayo de 1993 en la Universidad de Sevilla. 


\begin{abstract}
"Busco un centro permanente que no varíe lo que pienso de las cosas y de las gentes, yo necesito un centro de gravedad... yo necesito una seguridad".
\end{abstract}

Franco Battiato

Abordar la postmodernidad se nos presenta desde el principio como una tarea particularmente compleja, dada su peculiar naturaleza y empezando por el propio carácter semántico con el que se designa.

No parece que estemos ante una nueva corriente filosófica concreta dentro del pensamiento actual, o un movimiento artístico o "ismo" en la tradición de las vanguardias históricas, antes bien, podemos vislumbrar que nos encontramos ante un fenómeno, una situación que ha impregnado la vida contemporánea y se manifiesta de múltiples formas desde la década de los setenta, aunque sus orígenes pueden fijarse años antes.

La postmodernidad es un término que no parece aludir tampoco a nada específico, sino más bien a una concepción cultural propia de la sociedad de nuestros días, siendo precisamente esta ambigüedad o indeterminación, una de las características que definen por negación - valga la paradoja- el estado postmoderno.

Por otra parte, hablar de postmodernidad implica cierto riesgo, pues no existen todavía suficientes elementos de juicio que permitan ofrecer un corpus teórico sólido y menos aún unas conclusiones. A lo más que se puede aspirar por ahora, es a señalar o detectar ciertos indicios de una nueva situación, de que algo en verdad ha sucedido, aunque no podamos precisar bien sus perfiles.

Síntoma de que algo ha pasado es evidente, y se ha puesto de manifiesto a través de las crisis de los valores relacionados con la idea originaria de la modernidad, propulsada desde los postulados de la razón ilustrada, tal como ha sido analizado en el campo del pensamiento por Lyotard, Haberman, Baudrillard o Vattimo, por citar a sus máximos exégetas, o en el área de las artes plásticas por Charles Jeneks o Leo Steinberg 1 .

Uno de los filósofos más representativos de la postmodernidad, el italiano anteriormente citado Gianni Vattimo, creador de la teoría del "pensamiento débil", defiende, en cuanto al hecho de que el hombre de hoy proyecta más hacia el presente que hacia el futuro incierto, que éste no pretende modificar el destino sino incidir en su realidad manteniéndola, y considera nuestro tiempo como "ya

1. A.A.V.V.: La Postmodernidad. Ed. Kaíros, Barcelona, 1985. 
no moderno", donde el reto estriba en vivir sin una noción de la historia como progreso, característica ésta cara al concepto de modernidad. Ello significa una ruptura con respecto a la concepción de la historia como un proceso de hechos lineales y evolutivos, en el que un determinado momento histórico será superado por otro aún más perfecto que el anterior, siendo sustituido por un espacio donde acontecen proyectos múltiples, una pluralidad frente a la vocación unificante del pensamiento moderno, negando cualquier interpretación totalizadora en pro de un pensamiento limitado, débil y fragmentado ${ }^{2}$.

Por su parte el también filósofo francés, Jean Francois Lyotar, responsable, con su famoso ensayo "La condición postmoderna" publicado en 1979, de la divulgación del término, nos dice "hemos de acostumbrarnos a pensar sin moldes ni criterios".

El mundo tecnocrático en que vivimos, propio de las sociedades industriales ha demostrado que el único valor vigente y admitido es aquel capaz de ofrecer resultados, lo cual nos lleva al positivismo más radical y pragmático. Sin embargo, paradójicamente las consecuencias que se derivan del progreso científico y técnico, comprobamos que no son convincentes, o no lo son en la medida de satisfacernos plenamente. La situación postmoderna es en parte, producto de la crisis humanística establecida a partir de la concepción de los moldes creados en la ilustración, tal como han puesto de relieve las tesis de la corriente estructuralista y la Escuela de Francfort. Esto es, el fracaso de los tres grandes fundamentos humanistas que a partir del "siglo de las luces" se confió al progreso como fruto de la razón moderna y al proyecto de mejoramiento del hombre. O sea, fracaso de la política liberal, fracaso de la idea del trabajo como instrumento de avance económico, y fracaso y escepticismo en los ideales del marxismo. Todo esto se podría resumir en esta pregunta: ¿por qué continuar el crecimiento científico y tecnológico si no garantiza la liberación del hombre y su realidad espiritual, si en definitiva, no es humanista? Algo que se traduce en la siempre vigente reflexión: ¿De qué sirven los conocimientos, el progreso del hombre, si no mejora y repercute en su vida en el grado en que desea... si no es feliz?

Asimismo Lyotard coincidiendo con Baudrillard en la clausura de la sociedad en favor del individuo y la subjetividad, nos dice que "las sociedades han perdido el sentido de su destino, creen que el devenir no tiene finalidad, por eso en lugar de prepararse sobre el futuro, se interrogan por las condiciones de su representación, su espacio y su tiempo". Ideas, que si nos fijamos, concuerdan también con las bases defendidas por Vattimo acerca del "pensamiento débil" 3 .

2. Véase VATTIMO, G.: El fin de la modernidad. Nilismo y hermenéutica en la cultura postmoderna. Ed. Gedisa, Barcelona, 1986.

3. Véase LYOTARD, J.F.: "La naturaleza del lazo social: La perspectiva postmoderna", en $\mathrm{La}$ condición postmoderna. Ed. Cátedra, Madrid, 1987. 
Son muchos los interrogantes que nos asaltan ante el fenómeno de la postmodernidad. ¿Es una moda, un ismo, un invento, un nuevo período? ¿Postmodernidad está relacionado con el concepto postindustrial? -con lo cual se reivindicaría implícitamente la noción de progreso como consecuencia de la revolución industrial-.

Si así fuese, y en todo caso, habría que aplicarlo con un sentido restringido; pues hablar de época postindustrial sólo es lícito teniendo presente a un número limitado de países que han alcanzado el pleno desarrollo, países principalmente pertenecientes a Europa, Estados Unidos y Japón, el resto está en vías de lograrlo.

¿Entonces, que es la postmodernidad? Empecemos por el término, de por sí un tanto ambiguo como señalamos al principio; pues si desde un punto de vista etimológico y por su prefijo -post- parece que está claro que alude a "después de", en este caso, lo "moderno" tomaría entonces una categoría temporal como punto de referencia o de partida, que en cierto modo ya indica una contradicción, -la muerte de la historia en el sentido de la indiferencia hacia su concepto mítico con mayúsculas, donde se daba por supuesto una verdad de la misma conocida por todos, una historia en continuo avance y conquista- desde el punto de vista del significado, no todos entienden lo mismo. Así desde el campo estético, para algunos sólo puede aplicarse a las manifestaciones arquitectónicas como consecuencia del agotamiento del "estilo internacional", tal como Charles Jeneks sostiene, siendo desde la arquitectura y a partir de 1972, cuando el término tomó carta de naturaleza a raíz de la aparición de su libro "Arquitectura Postmoderna" en 1977, año en el que también el 6. certamen de la Documenta Kassel le dio legitimidad convirtiéndose en portavoz y testigo de que algo había aparecido ${ }^{4}$.

Por otra parte el vocablo Postmodernidad parece compartido por sinónimos como "Tardomoderno, Postvanguardia o Transvanguardia" si bien estas dos últimas acepciones aluden más específicamente al arte generado desde los 70 . De todo esto, lo que si parece ser evidente, es que la postmodernidad se entiende como lo que va detrás de lo Moderno, ante lo cual se hace entonces necesario preguntarse ¿qué se entiende por moderno? La idea de lo moderno es dual, según la apliquemos, bien como espacio o período cronológico, bien con un significado filosófico como categoría estética. Si tomamos la modernidad como fase temporal, hacemos referencia a un tiempo que tiene su origen en la Revolución Industrial, acaecída en los prolegómenos de la Revolución Francesa, que trajo consigo un cambio mental que modificó las creencias y pautas de comportamiento. Si por el contrario, contemplamos el concepto de modernidad como categoría estética,

4. JENEKS, C.: El lenguaje de la Arquitectura postmoderna. Ed. Gustavo Gili, Barcelona, 1980. 
ésta aparece identificada con las vanguardias históricas y su proyecto configurador de la realidad cotidiana y material, algo fácilmente verificable leyendo los programas de la Bauhaus y el constructivismo. Tanto un criterio como otro, temporal o estético, lo que sí parece es que hoy son obsoletos. Así el espíritu de novedad que animaba a la vanguardia histórica en esa sucesión continua de ismos, a partir de 1945, mostró signos certeros de desgaste irreversible. Desde entonces, más que movimientos cabría hablar mejor de tendencias, muchas de las cuales no son más que relecturas o derivaciones inmediatas de los ismos anteriores a la Segunda Guerra Mundial. Desde una perspectiva filosófica, visto el descrédito de las ideologías en sus intentos por lograr una vida más justa y mejor, la modernidad como motor emblemático de progreso, aparece vacío de contenido, reducida al mero formalismo de un propósito no conseguido que ha conducido al escepticismo y a la reserva de la razón, lo cual significa renunciar a todo aparato crítico y por tanto a la permisividad total en su concepción de "todo vale" o "todo es lícito", pues se ha suprimido todo criterio ideológico, ético y estético. Dicha postura, es una de las claves para entender la postmodernidad, en su negación de crear futuro y aceptar lo inmediato en su contundente realidad del "aquí y ahora", abdicando al deseo tantas veces proclamado de cambiar la vida recuérdese a Rimbaud y Marx - en pro del disfrute mayor y mejor de lo que hay a nuestro alrededor, en franca actitud hedonista y a la mayor gloria del bienestar. A propósito de esto creo interesante reproducir unas declaraciones de Almodóvar: "Ahora no hay movida, sino una necesidad de divertirse. Hay una cosa que está de moda y es el placer".

Todas estas características hacen del creador postmoderno, que decline los proyectos utópicos y trascendentales, concentrándose en la propia realidad y entendiendo el arte, sobre todo como "voluntad de vida" antes que como voluntad de estilo, en todo caso sería "un estilo de estilo", siendo precisamente el ecleticismo interdisciplinar en todos los órdenes de la creación artística una de las características visibles de la sensibilidad postmoderna, de ahí también que sea el vitalismo uno de los rasgos definitorio de los años ochenta.

La actitud crítica, de reproche o desconfianza para con la modernidad, ya tuvo sus antecedentes en la propia época de las vanguardias históricas. Existiendo conciencia por parte del artista de las contradicciones que había entre sus proyectos y la realidad resultante de ellos, recuérdese a título de ejemplo ilustrativo al grupo surrealista y sus escisiones a favor de "un surrealismo puro" y un "surrealismo al servicio de la revolución". Estas refutaciones se agudizaron pronto $y$ en un grado mayor a partir de la postguerra, lo cual no quiere decir que se abandonasen las tentativas de crear nuevas alternativas y propuestas. Ello es fácilmente comprobable si examinamos los años 60 , en que las condiciones económicas parecían aconsejar una vuelta optimista a la efectividad de la van- 
guardia, en este caso "Neovanguardias", dentro de las cuales brillaría con singular fuerza la cultura Pop de tanta repercusión y trascendencia. No obstante, esa momentánea ilusión pronto se vino al traste, y a la "Década prodigiosa" le siguió la "Década del desencanto", por emplear un concepto que en España a raíz de la película de Jaime Chavarry alcanzó enorme fortuna. Los años 70 pusieron en evidencia la conflictiva realidad y sus fisuras: desmoronamiento de los modelos sociales, crisis energética, carrera armamentística, desempleo masivo -generado en parte por las nuevas tecnologías- deterioro ambiental y del entorno natural, que hicieron surgir los movimientos ecologistas-, desarrollo de la llamada "ingeniería genética" y su potencial uso manipulador, etc... La mayoría de estos males se mantuvieron en los años 80 , en la era de la postmodernidad, acentuándose en algunos casos, lo cual provocó una política conservadora claramente representada por los gobiernos de Ronald Reegan y Margaret Thatcher, mientras que por otro lado, la respuesta frente al desasosiego producido por la carencia en que apoyarse ha hecho que la sociedad se detenga en la realidad más inmediata y cercana, esto es en nosotros mismos y en todo aquello que conduce al mejor estado, potenciando el individualismo, de ahí el énfasis hedonista en el que se desea vivir, y la cómplice e insistente proclama por parte de los medios de comunicación y de modo particular la televisión. Surge la generación del bienestar, la entronización de lo divertido y el placer, como valores supremos llegando a alcanzar validez cultural. Los objetivos se tornan parciales, limitados, renunciando conscientemente a todo proyecto globalizador.

El espíritu de novedad que animó a la vanguardia histórica en esa aparente sucesión vertiginosa de ismos, a partir de 1945 mostró signos inequívocos de agotamiento. Más que de movimientos cabe referirse desde entonces a tendenciàs, muchas de las cuales no son más que una consecuencia inmediata de las corrientes anteriores a la Segunda Guerra Mundial. De este modo ¿cómo no ver al Expresionismo Abstracto como el heredero legítimo del Surrealismo Automático, o el Pop Art y el Art Conceptual en conexión con el Dadaismo, teniendo a la figura de Marcel Duchamp como su más ilustre y trascendental antepasado?

$\mathrm{Si}$ analizamos la realidad del artista y sus relaciones con la sociedad desde los años cuarenta para acá, constatamos que se han producido enormes cambios, sobretodo a partir de los años setenta. Estos, no sólo han afectado de manera personal a los creadores, sino también a su posición en la sociedad. Aquella actitud de héroe solitario -a pesar suyo- enfrentado a una sociedad que no le comprendía y le ere hostil en la época de entreguerras, ha quedado hoy en buena parte superada y neutralizada por la labor ejercida por la galería y la crítica.

El antiguo mercado de arte de las vanguardias estaba constituido por unos cuantos coleccionistas y marchantes que tenían más espíritu de artista que de comerciante, hombres como Durant Ruel, Paul Rosemberg, Ambroise Vollard, 
Henry Kahnweiller, o en nuestro país José Dalmau, sólo al final verían compensados sus esfuerzos y reconocimiento a su labor. Hoy día, un número no insignificante de artistas ha quedado a merced de los galeristas, los cuales parecen ser los encargados de crear y gestar las nuevas tendencias, para lo cual han invertido su capital y su eficacia propagandística con la complicidad de ciertas revistas y el respaldo en ocasiones de una crítica fácil. En este sentido el artista, puede decirse que se encuentra sometido a una planificación cercana al "marqueting", en donde sabe de antemano las reglas que tiene que aceptar si desea triunfar: estilo, periodicidad, tanto por ciento, oportunidad de exponer, pertenencia exclusiva a una galería... unas condiciones de las que sólo se liberará cuando su nombre y su obra haya alcanzado un prestigio y consolidación. La posición "ideológica" del artista postmoderno se presenta de forma un tanto ambigua manteniendo una actitud independiente con respecto a todo lo que supone el concepto de vanguardia de preguerra, lo cual no supone contrariamente a lo que podría pensarse en un primer momento, un corte radical con su legado, como se desprende de sus continuas citas formales a las mismas y sus reinterpretaciones, de ahí sus relecturas, variaciones, y su acción de palimpesto.

Teniendo en cuenta lo expuesto, se comprende bien el recelo hacia la modernidad y el descrédito consumado de las vanguardias, lo cual parece conducimos a deducciones pesimistas, entre las cuales se encontraría la muerte del arte, ratificando una vez más el famoso vaticinio del filósofo alemán. ¿Qué significa esto? ¿la desaparición del arte...? Necrófilos de turno se han apresurado a lanzar no sin cierta alegría masoquista y reveladora de su pequeñez mental su epitafio. Algo por lo demás nada nuevo, pues como he aludido, ya Hegel lo había hecho antes frente a la ruptura de equilibrio entre materia y espíritu mantenido desde el clasicismo y la ineficacia, a partir de entonces, de satisfacer las necesidades interiores. No, el arte y pese a las apariencias no está muerto, lo que sí está inerte son los pilares ideológicos que lo sustentaban, especialmente la vanguardia como arma redentora a los problemas del hombre, y la puesta en entredicho de su operatividad bien intencionada. Se ha perdido la fe como instrumento transformador de la sociedad. ¿Por qué entonces seguir utilizando el término de vanguardia? Bien podemos decir que dentro de la jerga artística sirve más que nada para expresar la idea de lo último que se está haciendo. En este sentido resulta particularmente elocuente que Bonito Oliva proclame a la "Transvanguardia como la actual vanguardia", y en un plano más cínico todavía, alguien no ha tenido ningún reparo y escrúpulo para afirmar que "la vanguardia es el mercado".

Podemos responder ya y al hilo del panorama descrito hasta aquí a ¿qué es la postmodernidad?... La respuesta la voy a dar, o mejor, la dio ya Baudelaire al referirse paradójicamente a la modernidad, algo que en ningún modo debe tomarse como una definición al uso, pero que sin embargo posee la virtud de 
recoger un conjunto de "elementos" que a nuestro criterio asumen de manera esencial y paradigmática lo que podría considerarse como condición postmoderna. Es decir sería entre otras cosas -y tomo literalmente las palabras del autor de las "Flores del Mal"-, "lo fugaz, lo contingente, buscar lo poético en lo transitorio, y lo eterno en lo temporal".

La Postmodernidad, encierra una gran cantidad de factores que hace difícil su formulación de una forma nítida y unitaria, siendo precisamente ese carácter inasible, difuso, plural y fragmentario, lo que hace visible y distintivo su perfil, o si se quiere, su condición diferencial con respecto a la imagen compacta y homogénea de la vanguardia histórica.

Todas estas circunstancias, hacen del artista postmoderno que renuncie a los proyectos utópicos, concentrándose en su propia realidad y entendiendo el arte sobre todo como "voluntad de vida" antes que como voluntad de estilo, de ahí que sea el vitalismo una de las características más definitorias de la pintura de los ochenta. Las ideas tan consustanciales a la vanguardia histórica de progreso, novedad, experimentación, etc., han sido suplantadas por el deseo inaplazable de pintar, de crear, de expresarse, para lo cual todo es lícito y está permitido. La historia del arte se convierte en memoria visual, en herencia de la cual el artista tomará libremente la parte que más le interesa, sin ningún sentimiento de culpa, de ahí los reciclajes y los "neos". Su posición, es una escapada hacia adelante, no hay metas, no hay caminos, no hay objetivos, sólo se tiene la certeza de que se está en ruta, de que el camino se hace al andar, como nos recordara ese gran poeta filósofo que fue Antonio Machado.

De este modo, la condición y sensibilidad postmoderna, si tuviéramos que traducirla en el plano práctico de la pintura, podría resumirse -sin ánimo de exhaustividad- en cinco puntos esenciales para un primer acercamiento y comprensión:

1. - Un sentido hedonista expresado en la búsqueda del placer en la propia obra de arte, en el gusto que siente el artista en su elaboración. Algo que ya quedo explícito en la "vuelta a la pintura", tanto en sus propuesta de "soportesuperficie" de los años setenta, como en la recuperación de la imagen figurativa.

2. Regreso a la figuración, pero un retorno que nada tiene que ver con el realizado en los años sesenta y su concepción objetiva y realista, antes al contrario es una figuración que apela a la imaginación, a lo narrativo, a lo fragmentario, donde la figura humana y el objeto comparten por igual el protagonismo espacial del lienzo.

3. - Una vuelta a la naturaleza, sobre todo constatada en buena parte de la producción de principios de los años ochenta.

Visto los resultados del progreso, de la realidad económica en su expresión más prosaica de un capitalismo feroz que todo lo controla y supedita, del fracaso 
político que toma en el mejor de los casos a la democracia y al liberalismo como remedio de lo menos malo, de la guerra permanente en alguna parte del globo... hace que el artista a la manera romántica, y desde su punto privilegiado, como ya ocurriera con el expresionismo germánico de la época de entreguerras, se dirija hacia una búsqueda de la pureza inexistente en la vorágine de la ciudad y que tiene en la naturaleza, en lo primitivo, en lo arcaico, en una forma de retorno a los orígenes, su mejor "esperanza", su mejor acceso para entrar en el "Paraíso perdido".

4.- La obra de arte se concibe sin dogmas, sin jerarquías, no exclusivista, con un deliberado "carácter abierto", que permite múltiples interpretacionès y lecturas como variadas son sus estrategias. No persiguiendo tampoco el prurito, tan caro en otros tiempos, de la originalidad.

5. La filosofía del artista postmoderno, su concepto de verdad, es lo que pasa y nada más, el presente, el momento mismo de la creación, y si lo vives, vibras.

\section{NOTAS SOBRE LA POSTMODERNIDAD EN ESPAÑA}

Acercarnos a la pintura española realizada en los años ochenta, presupone tener en cuenta, antes de nada, el nuevo marco político que vive el país desde 1978 en su recuperación de la democracia, lo cual hizo posible no sólo la normalización de nuestra situación institucional, sino que propició de forma acelerada la regulación de la vida cultural, dando debido cauce a una generación de artistas jóvenes con una gran vitalidad creadora, algunos de los cuales han conseguido un reconocimiento internacional. Una vez establecidas las condiciones prioritarias de libertad, el panorama artístico formado a lo largo de esta dinámica década de los ochenta, se vio jalonado por unos hechos cuya trascendencia y recuperación es necesario señalar para comprender la personalidad y el carácter de la postmodernidad en nuestro país ${ }^{5}$.

Como era de esperar, los profundos cambios producidos en España en todos los órdenes, y por tanto, también en el artístico, hicieron posible casi por primera vez, que nuestros artistas en mayor o menor medida se integraran en los círculos internacionales. Evidentemente ello responde a un conjunto de circunstancias y de causas diversas que sería injusto silenciar, como son entre otras, las múltiples

5. A.A.V.V.: Calidoscopio español (arte joven de los años ochenta), Catálogo, Fundación General Mediterránea, ed. Laredo, Madrid, 1984.

POWER, K.: "Los gozos y las sombras", en El paseante, n. ${ }^{2} 118-19$, Madrid, 1991.

DIEGO, E.: "Al fin cosmopolita. (La aparente internacionalización del arte español en la última década), en Revista de Occidente, n. ${ }^{\mathbf{2}}$ 122-123, Madrid, 1991. 
iniciativas llevadas a cabo por la administración, tanto si se trata del Ministerio de Cultura de la nación como las efectuadas desde las distintas autonomías e instituciones públicas y privadas. En este sentido el número de exposiciones organizadas por el Estado ha sido, en términos globales, altamente positiva. Esta necesaria y urgente labor, que mantuvo la mayoría de las veces sus sedes principales en el Palacio de Velázquez y en el recién creado Museo Nacional Centro de Arte Reina Sofía, se vio simultáneamente completada por otras entidades institucionales del resto de España como el I.V.A.N. o Instituto Valenciano de Arte Contemporáneo, o el C.A.A.M., Centro Atlántico de Arte Moderno de Las Palmas de Gran Canaria, si olvidar la labor emprendida desde hacia tiempo por algunas galerías y sobre todo la extraordinaria actividad realizada por la Fundación Juan March, dedicada desde los años setenta a dar a conocer las principales figuras y movimientos internacionales de la vanguardia histórica, y la no menos meritoria y decisiva en su objetivo de difusión puntual, de la Caja de Pensiones en sus respectivas sedes de Barcelona y Madrid, esta última institución especializada sobre todo en presentar a una serie de artistas actuales de una gran categoría, teniendo como gala entre otros proyectos el haber patrocinado exposiciones tan representativas de la época que estudiamos como "La Transvanguardia Italiana", la corriente alemana conocida como "Nuevos Salvajes" - ("Origen y Visión". Palacio Velázquez)-, y algunas de las personalidades más importantes de estos últimos años como el carismático Josep Beuys, Jiri G. Dokoupil, Yves Klein o el norteamericano David Salle. Así mismo referencia inexcusable es la creación de 1982 de A.R.C.O., la feria internacional de arte anual organizada en Madrid, que no sólo cumple una función de muestra o escaparate de la producción y novedades nacional o internacional sino que ha influido notablemente en la creación de nuevas fórmulas de entender el mercado artístico en nuestro país estableciendo criterios de gestión más operativos en las galerías, impulsando el coleccionismo y la recepción crítica. Por otra parte el número de publicaciones de arte especializadas, catálogos nacidos a partir dè exposiciones, se ha visto notablemente acrecentado. Las primeras poniendo al alcance de una mayoría una información actualizada de cuanto acontece en el mundo del arte, las segundas dando cuenta directa, bien de forma individual bien en colectiva, de lo que se está haciendo a todos los niveles en materia de artes visuales.

También es justo reconocer el considerable esfuerzo realizado en los últimos años para divulgar nuestro arte en el exterior, siendo en este sentido dignas de mencionar entre otras, las exposiciones organizadas como "Nueva Imagen de España”, presentada en el Museo Guggenheim de Nueva York en 1979, y cuya comisaria fue Magarit Rowell, antigua directora de la Fundación Miró de Barcelona, en la que se reunieron artistas de dos generaciones como Darío Villalba, Teresa Gancedo, Jordi Teixidor, Sergi Aguilar, Carmen Calvo, Miquel Navarro, 
Guillermo Pérez Villalta y Zuch; la exposición "Nueva Figuración Española" que recorrió varias ciudades inglesas en 1982 con artistas como Luis Gordillo, o la también itinerante "Arte Español Actual", exhibida en Francia a lo largo del año 1984 teniendo en su nómina a pintores como Miquel Barceló, José María Boto, Miguel Campanao, José María Sicilia o Manuel Quejido, para finalizar en la edición de Europalia dedicada a nuestro país en Bruselas en 1985, donde el arte español en general y especialmente el contemporáneo se le dedicó una particular atención.

Lamentablemente esta a todas luces urgente y obligada campaña de promoción del arte español desarrollada sobre todo durante el primer lustro de los ochenta, no ha tenido la continuidad que debiera, y aquí podríamos empezar por comentar las deficiencias que hacen que todavía nuestro arte no se conozca ni ocupe el lugar que en realidad le corresponde, a excepción de una docena de artistas. Quizás lo primero que habría que cuestionarse es el hecho trascendente y siempre polémico de la identidad del arte español, de la ausencia de unas características propias que pongan de relieve sus peculiaridades y personalidad, del mismo modo que Francia, Italia o Alemania, por citar a los países más cercanos a nuestro entorno cultural, creadores a lo largo del presente siglo de distintos movimientos, mientras que España ha basado fundamentalmente su aportación a través de grandes individualidades, las cuales han desarrollado su genio y obra fuera del país. Por otra parte y como con certera clarividencia dijo Simón Marchan "a nuestro arte le sobra Historia, pero le falta la tradición de lo nuevo".

El pasado reciente, me refiero desde 1900 hasta casi ayer mismo, y salvando como siempre las figuras que de un modo paralelo compartieron las mismas inquietudes estéticas avanzadas que en el exterior, el arte español ha vivido ensimismado en una práctica tradicional y clásica de la pintura, por otra parte y en general, de excelente calidad pictórica. En España no existieron movimientos de vanguardia que cristalizaran en verdaderos grupos compactos, con un programa ideológicamente definido y de alternancia radical a lo que predominaba en esos momentos -me refiero al primer cuarto de siglo-, siendo mucho más exacto y sobre todo preciso emplear el concepto de "modernidad", la cual, sólo en algunos casos alcanzó un verdadero espíritu vanguardista de ruptura y compromiso.

En España así mismo, y como es notoriamente sabido, nuestros mejores y más significativos artistas marcharon al extranjero desde principios de siglo, principalmente a París, no ejerciendo prácticamente influencia en su patria hasta muy tarde. Esta ausencia de nuestros mejores creadores se vio todavía negativamente reforzada por las circunstancias políticas en España desde la Guerra Civil hasta 1975, impidiendo una comunicación cultural vital y manteniéndonos aislados hasta fechas relativamente próximas. 
Todas estas circunstancias de nuestra realidad artística dentro del contexto político, económico y sociocultural que ha vivido España, pensamos que sirven como punto de reflexión y de partida a la hora de poder comprender y valorar la singular naturaleza y carácter del arte realizado durante bastante tiempo en este país.

Al examinar el panorama artístico de los años ochenta en España comprobamos en principio que a diferencia de lo acontecido en Italia con la Transvanguardia lanzada por Bonito Oliva, el Neoexpresionismo Alemán o la "Nueva Imagen" norteamericana -de la cual por cierto se pudo ver una excelente antología en el Palacio de Velázquez en 1983 con el título "Tendencias de Nueva York"aquí no han existido movimientos análogos, lo cual y en cierta forma era casi lógico, dada la carencia de un pasado verdaderamente renovador y la no menos importante falta de conciencia y conocimiento de nuestro arte por parte de nuestros artistas más jóvenes -aludo al realizado durante la época de las vanguardias historias-, amén de la escasez de infraestructura necesaria para crear las condiciones mínimas de manera que nuestros artistas pudieran configurar una propuesta válida y con identidad propia. Las referencias de mayor trascendencia y de las que en buena medida se nutre lo mejor de nuestra vanguardia más inmediata $-\mathrm{y}$ tomo aquí el vocablo de vanguardia de modo absolutamente genéricohan sido al margen, como ya es habitual, de figuras que optaron por una "bella aventura personal", tal como dijera con sentimiento Eduardo Arroyo, y traigo aquí la cita de este artista por ser el mismo un buen ejemplo de lo afirmado, son los grupos "Dau al Set", y sobre todo "El Paso".

Mientras la vanguardia artística internacional de los setenta estuvo casi presidida por las tendencias del Conceptualismo y el Minimalismo, hasta que al final de la década se produce cierta recuperación de la pintura a partir de lo que se conoce como "Soporte/Superficie" surgido en Francia, en España se deja sentir el conceptualismo teniendo como centro principal Barcelona, ciudad cuyo pasado artístico más inmediato contaba con la herencia surrealista de preguerra continuaba en cierta forma y en sus comienzos por el grupo anteriormente citado del "Dau al Set"- y sobre todo con un núcleo importante de artistas representantes del informalismo, del cual se pudo ver en 1991 una interesante muestra en el centro de Santa Mónica. Madrid por el contrario carente de esa tradición informalista se decantó en líneas generales para la neoabstración y por una neofiguración que en gran parte contenía un fuerte sentido crítico y comprometido contra el Régimen, lo cual desaparecería a partir de 1975.

Mientras tanto la capital del estado se había convertido en el centro de trabajo y residencia de un número de artistas procedentes de todos los puntos de la geografía española, entre los cuales hay que destacar el grupo de jóvenes que ven en la obra de Luis Gordillo la solución a la situación en que se encontraba la 
pintura en España en estos momentos. De este modo el pintor sevillano se convirtió en un faro a seguir desde la óptica de una nueva figuración portadora de una serie de nuevos valores pictóricos, entre los que se encontraba el de la vuelta a la imagen figurativa, contribuyendo ello al inicio de lo que podría considerarse como pintura postmoderna en España, bien entendido esto no como una tendencia al uso, sino a un modo de concebir y practicar el arte de manera diferente a como se había hecho hasta entonces. Este importante cambio quedó perfectamente reflejado en dos exposiciones, que de forma emblemática representaron bien el nuevo rumbo que tomó la pintura española, cuyo resultado más significativo fue la renuncia al informalismo en pro de un gusto prioritario por la figuración, que tomará desde ahora un concepto renovador y audaz bajo el epíteto todo hay que decirlo, pues se ha convertido un poco en cajón de sastre y se emplea en bastantes ocasiones como gratuito comodín- de "neofiguración". Me refiero a la exposición organizada en la madrileña galería Juana Mordó en febrero de mil novecientos setenta y nueve con el nombre de "1980", donde participaron entre otros Carlos Alcolea, Chema Cobo, Gerardo Delgado y Manolo Quejido, y la más memorable, si cabe, de "Madrid. Distrito Federal" 1980, celebrada en el Museo Municipal y cuyos comisarios fueron el crítico Juan Manuel Bonet y el profesor Ángel González García que incluía obra de Juan Navarro Baldeweg, Alfonso Albacete, Eva Looz, Juan Antonio Aguirre, Pancho Ortuño, Adolfo Scholsser, G. Pérez Villalta, Santiago Serrano y Enrique Quejido. Dos años más tarde la Caja de Pensiones consiguió reunir bajo el proyecto de "26 pintores, 13 críticos. Panorama de la Joven Pintura Española" a buena parte de los autores que en la actualidad gozan del mayor interés: Federic Amat, Xavier Grau, Juan Usle, Chema Cobo, Miguel Campano, Miquel Barceló, Ferrán García Sevilla, Jordi Teixidor, José María Broto, Gerardo Delgado, etc. En todas estas exposiciones se apreciaba una mezcla de tendencias como rasgo más destacado, una coexistencia que no hacía sino anunciar lo que pronto sería una de las características distintivas de la nueva sensibilidad pictórica de los ochenta reflejada en la simultaneidad y prolífera aparición de "Neos" -Neoexpresionismo, Neofiguración, Neoabstracto, Neodada, Neoconceptual, Neogeo, Neobarroco, Deconstrucción, estas dos últimas denominaciones ya surgidas casi al final de los ochentasujeta al amparo de la más dispar revisión y mistificación, y sobre todo al deseo todopoderoso por parte del artista de querer pintar con plena libertad, rechazando todo dogmatismo e interpretación unívoca supeditada a cualquier dictado y dentro del más entusiasta espíritu ecléctico.

Así pues, la postmodernidad plástica española, expresada en el marco del concepto "Nueva Figuración", asume una pluralidad de registros formales y estilísticos basados en esa libre subjetividad mencionada de cada artista, cuyos motivos de inspiración y referencia son tan múltiples, elécticos y variados como 
su propia obra. La "línea fría" se alterna con el expresionismo más incendiario, lo figurativo y lo abstracto fluctúan al unísono e incluso comparten la misma superficie del cuadro, se asiste a una reelaboración iconográfica que tiene en la historia del arte, y de modo especial en la vanguardia cosmopolita, su origen, sin olvidar intentos de búsqueda, por parte de algunos artistas, en lo local y regional.

Planteadas así las cosas, podemos admitir que España se encuentra actualmente en un buen momento, pleno de expectativas, con una generación de artistas jóvenes, emprendedores, totalmente homologables -ipor fin!-con el resto de los pintores y con lo que se está haciendo internacionalmente, algunos de los cuales, y como he señalado al principio, han alcanzado un amplio reconocimiento y admiración fuera de nuestras fronteras con el beneplácito de la crítica más exigente y atenta. No obstante, y ante un futuro tan esperanzador como incierto, cabe reflexionar una vez más sobre algunos aspectos que inciden sobre las estructuras y la trama de nuestro arte, haciendo que todavía disten de ser las adecuadas para un funcionamiento normal como el existente en otros ámbitos europeos. Al arte español nunca le han faltado talentos, se suele afirmar con frecuencia que este es un país de pintores, sin embargo lo que ya no se dice, es que el artista español se encuentra casi siempre en inferioridad de condiciones y en un estado de desconcierto, propio de un país cuyo retraso proverbial e idiosincrasia hacen terriblemente deficitario todo proyecto de articulación eficaz en su funcionamiento, encontrándose inmerso en una sociedad y una cultura de masas cada vez más alineante y sometida al irracional consumismo propio de los países desarrollados industrialmente.

En este delirante contexto se han producido dos hechos que creo dignos de subrayar, y que han afectado de manera directa al mundo del arte reciente. Por una parte se ha asistido y participado en un fenómeno mundial de especulación artística sin precedentes, propiciando un mercado irreal donde la obra ha alcanzado unos precios totalmente desmesurados e injustificables, que en nuestro país ha quedado reflejado en lo que podría denominarse "síndrome Barceló", por el cual el artista joven y el no tan joven se ha dejado llevar ante el espejismo de una cotización a todas luces desproporcionada y hasta ahora impensable, sostenida las más de las veces por intereses ajenos al arte y emparentados con la inversión como simple producto de bolsa, estimulada en parte por el esnobismo del "impecable ejecutivo" o "yuppie". Afortunadamente esta irresponsable euforia especulativa, desde principios de los noventa, ha empezado a remitir volviendo las cosas a su cauce normal.

El otro problema, y éste no subsanado todavía, es el de la crítica del arte; excluyendo las excepciones de rigor, podemos afirmar sin temor a equívoco que, como señalaba atinadamente la reconocida crítica Victoria Combalía en un notable y jugoso artículo titulado "Estrategias de poder", escrito con la lucidez y el 
compromiso que la caracterizan, en España no ha habido aún un debate teórico sobre nuestro arte actual, es más el reconocimiento logrado por algunos privilegiados -ya saben, Barceló, Sicilia, García Sevilla, etc.- se ha hecho más a partir de valores económicos de cotización y a su incursión e un circuito internacional de galerías, que gracias a una sólida consideración crítica avalada desde el extranjero, como es costumbre ${ }^{6}$.

Esto creo que es particularmente preocupante, pues tenemos, en términos generales, un aparato crítico desolador, el cual adolece de capacidad de argumentación en lo que expone, sin un criterio serio y responsable con el que poder evaluar o negar la bondad de lo que se hace, quedando reducido las más de las veces a un discurso huero e ininteligible, cuyo lenguaje crítico y hermético impide tanto para el especialista como, sobre todo, para el profano saber con claridad lo que está diciendo. Así mismo, y esto todavía resulta en mi opinión más grave, cualquiera de las argumentaciones aplicadas se antojan polivalentes y útiles para "juzgar" por igual a otras realizaciones, lo cual hace todavía menos explicable y sospechoso el triunfo de unos y la total ignorancia para otros. Por otra parte una simple mirada por las revistas de arte y observaremos, casi siempre, la misma lista de nombres con la consiguiente apología reiterativa.

Mientras que no se establezcan unos criterios rigurosos y propios, dejando de repetir con más o menos fortuna la opinión del crítico reconocido de turno, a ser posible foráneo, el quehacer de gran parte de nuestra crítica quedará relegado a un ejercicio estéril, contribuyendo, sin querer, a hacer realidad la falaz y estúpida afirmación de "todo vale".

Mientras tanto, la confusión es quizás el síntoma más destacado a la hora de querer entender y explicarse determinados comportamientos y manifestaciones relacionadas con el arte, pero ello creo que no debe inquietarnos demasiado, por lo menos hasta el punto de obsesionarse y pensar que vivimos una época que como expresara Sartre con contumaz pesimismo acerca del hombre "es una pasión inútil"; tal vez sean los efectos de todo fin de siglo, como algunos se han aventurado a indicar. En todo caso y tomando las mismas referencias temporales decimonónicas, los resultados vistos desde la perspectiva actual fueron altamente positivos, y les aseguro que sus contemporáneos no lo creyeron ni lo percibieron así, sólo hay que dar tiempo al tiempo, él siempre tiene la última palabra; por lo demás procuremos gozar y gratificarnos con lo que se nos ofrece. ¡Qué importan ya las etiquetas, aunque ciertos productos pretendan todavía acaparar para sí ese difícil y abstracto concepto designado como arte!

6. COMBALIA, V.: "Estrategias de Poder", en El Guía, n." 11, octubre-noviembre, Barcelona, 1991. 


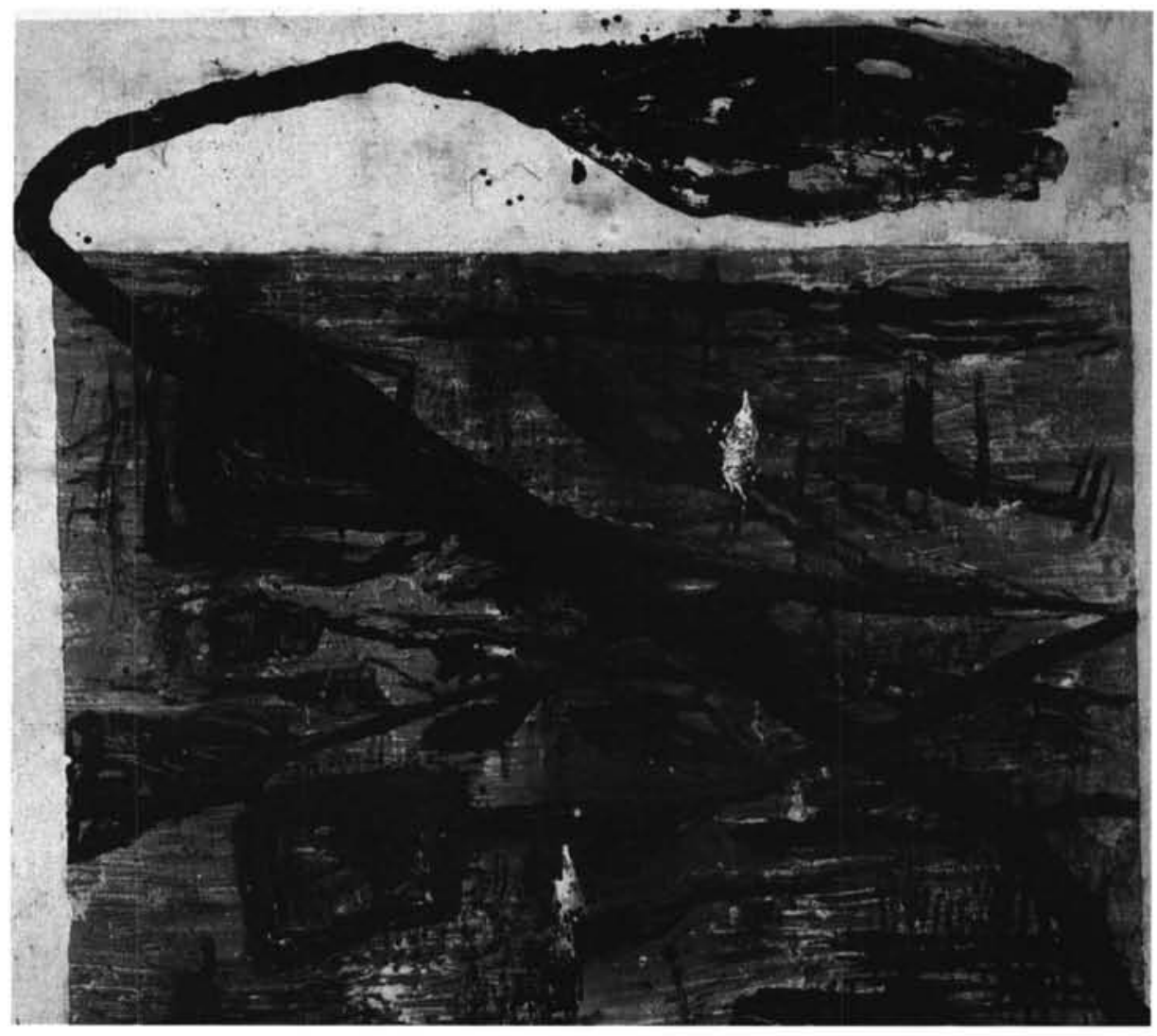

José María Sicilia, 1985. "Tulip 6". 


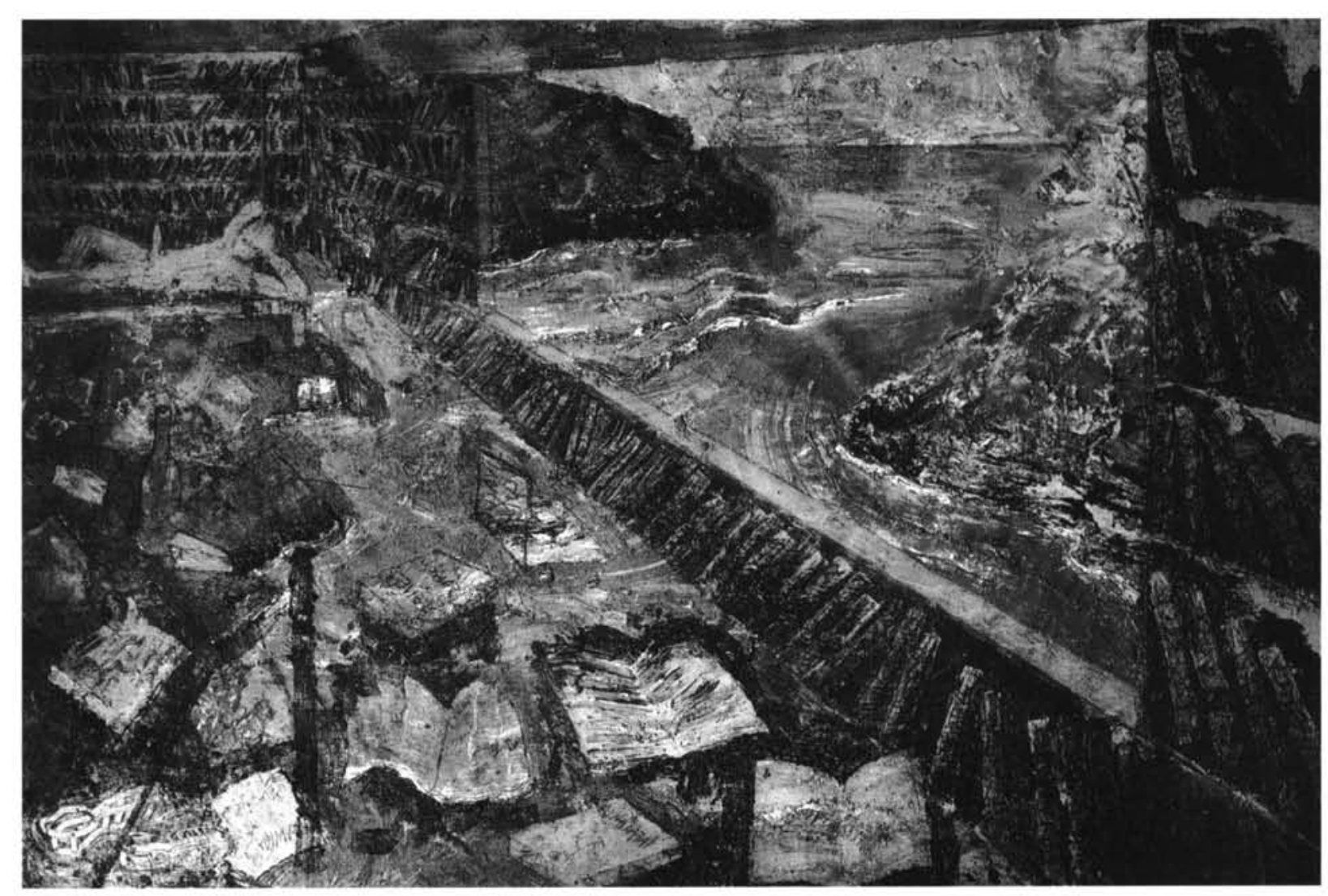

Miguel Barcelo, “El Amor Loco”, 1984. 


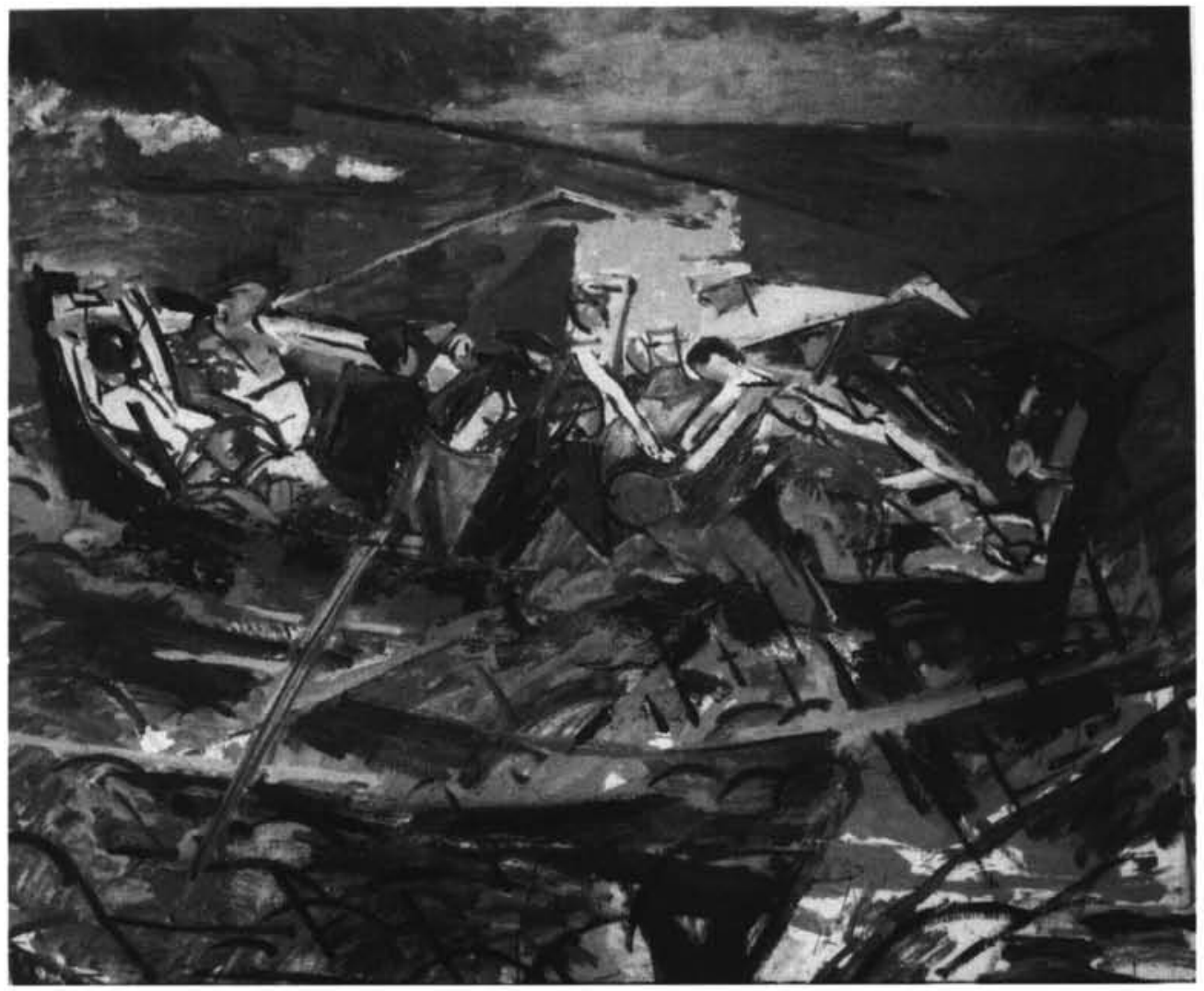

Miguel Angel Campano, "Naugrafío", 1982. 


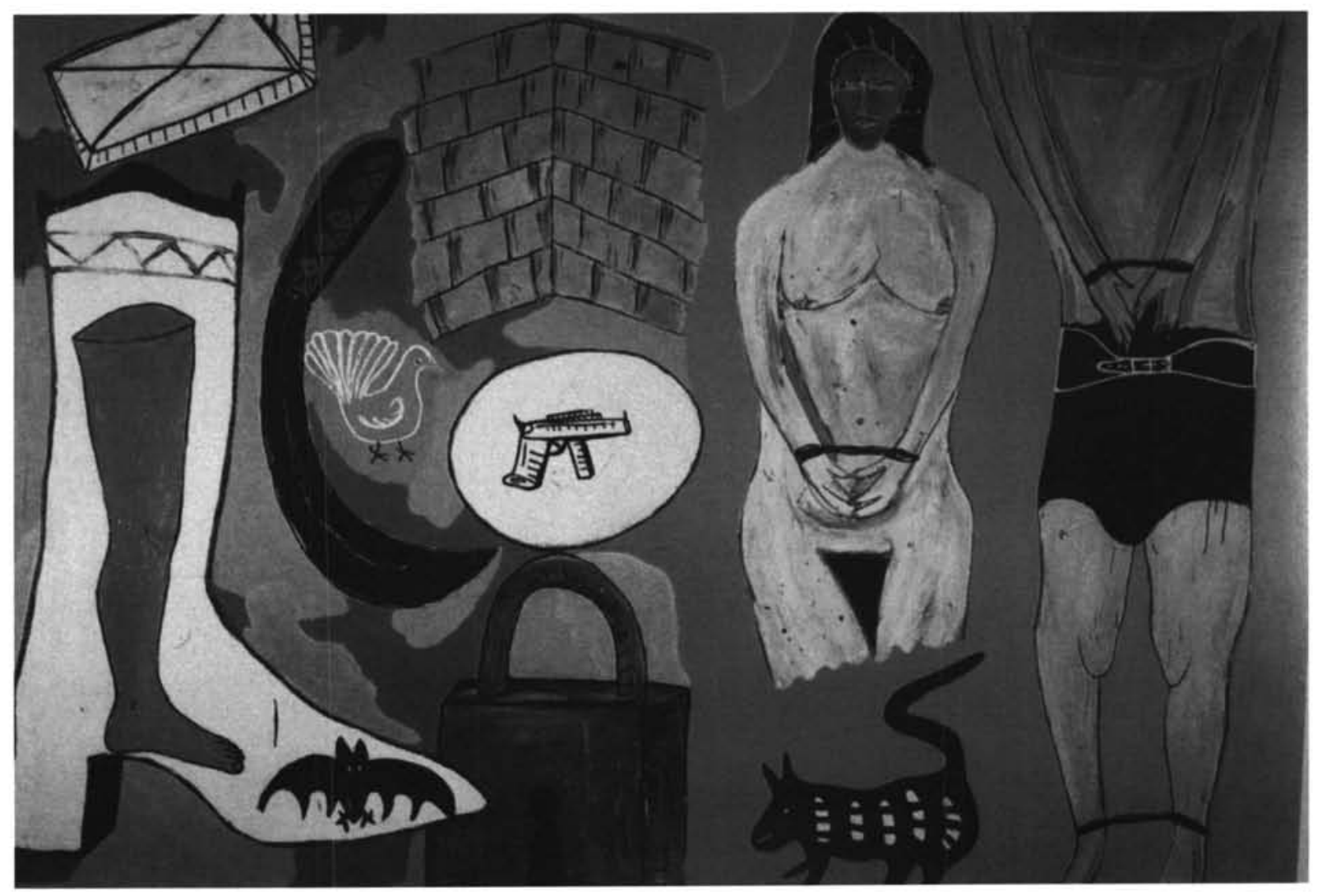

